\title{
Constant Amplitude of Prestressed Concrete Sleeper (PCS)Subjected to Three Coaches Train
}

\author{
SharulNizam I ${ }^{1, a}$, Afidah $\mathrm{AB}^{1, \mathrm{~b}}$, SitiHawa $\mathrm{H}^{1, \mathrm{c}}$, and MohdlkmalFazlan $\mathrm{R}^{1, \mathrm{~d}}$ \\ ${ }^{1}$ Faculty of Civil Engineering Universiti Teknologi MARA 40450 Shah Alam, Selangor, Malaysia \\ asharulchong_08@yahoo.com, bafida3342@salam.uitm.edu.my, 'shh@salam.uitm.edu.my, \\ ikmal601@salam.uitm.edu.my
}

Keywords: Prestressed Concrete Sleeper (PCS), Constant Amplitude, Rainflow counting method

\begin{abstract}
Prestressed Concrete Sleeper (PCS) is the main structural component in railways track. PCS is used to transmit the load from the train to the ballast. In this study, the pattern of load applied to the PCS was determined. The pattern of load is important as it affecting the design and lifetime of concrete sleeper. The raw data for load of train will produce variable amplitude value as the PCS will be experiencing the different type of loading. The value of raw data when the wheel of train hit the PCS will be higher than the raw data when the concrete sleeper is experiencing vibration due to incoming train. In this study, the pattern of load will be analysed to understand the behaviour of the load applied to PCS. Other than that, the variable amplitude value of raw data will convert into a constant amplitude value using a method of calculation. The determination of constant value amplitude will be divided into $\mathrm{N}$-section to finding the maximum and minimum value for the section. In addition, the actual number of cycle from the raw data will determined using Rainflow Counting method. This study can be further used for laboratory work as it's determine the suitable loading and cycle applied to the PCS under dynamic loading[1].
\end{abstract}

\section{Introduction}

Traffic congestion is one of the most problems faced by a developed country. Malaysia is one of the countries that are including and facing the same problem. As for Malaysia, the government has called us to use a public transportation for avoiding traffic congestion. There are many types of public transportation such as buses, trains, taxi and many more. For land transportation, trains become the choice for consumer due to the safety, efficient, planned and affordable[2]. It is necessary for providing a safe and sustainable land public system to improving the quality of people and economic growth. So, many technologies are use and adapt to design, construct and maintain the construction. It's also including the choice of type and the material use for construct to serve a long period. In this study, it focuses on the railway sleeper use by Malaysia's rail.

PCS is made from embedded prestressed tendon inside the concrete and used as railroad for railway. Before the PCS, stone block was used for the railways for examples, Stockton \& Darlington railway. Then, the railway transportation improve from stone block sleeper to timber sleeper railways. This type of sleeper is used across Europe for their railways. But due to many disadvantages of wooden sleeper, PCS has been the preferred options to replace it and used widely around the world [3]. Currently in Malaysia, the authority namely Keretapi Tanah Melayu Berhad (KTMB) has choosen option for PCS rather than wooden sleeper. In this study, it focuses on the PCS.

For Malaysia, KTMB is the main authorities for managing the railways system in West Malaysia. It has been operated since around 1885 when the Malaysia is ruled by British. At that 
time, the railway system is only use to transport tin. Before this, the railway system in Malaysia was run by Malayan railway administration until 1991, KTMB take over the duty of Malayan railway administration to run the railway system [4].

\section{Methodology}

Raw Data. The raw data was obtained from site measurement at Kajang-UKM railway station [5].The data has to be analyse first to determine the specific part of the raw data to be calculating. The whole raw data was obtained even before the train pass through the PCS. So, the data has to be analysing on the time the train pass through the PCS. This is the reason why the raw data need to be analysing first before being process. Data need to be cut from actual length to left only the important data involve in calculation. Figure 1 shows the data have been analyze to classify the section of N.

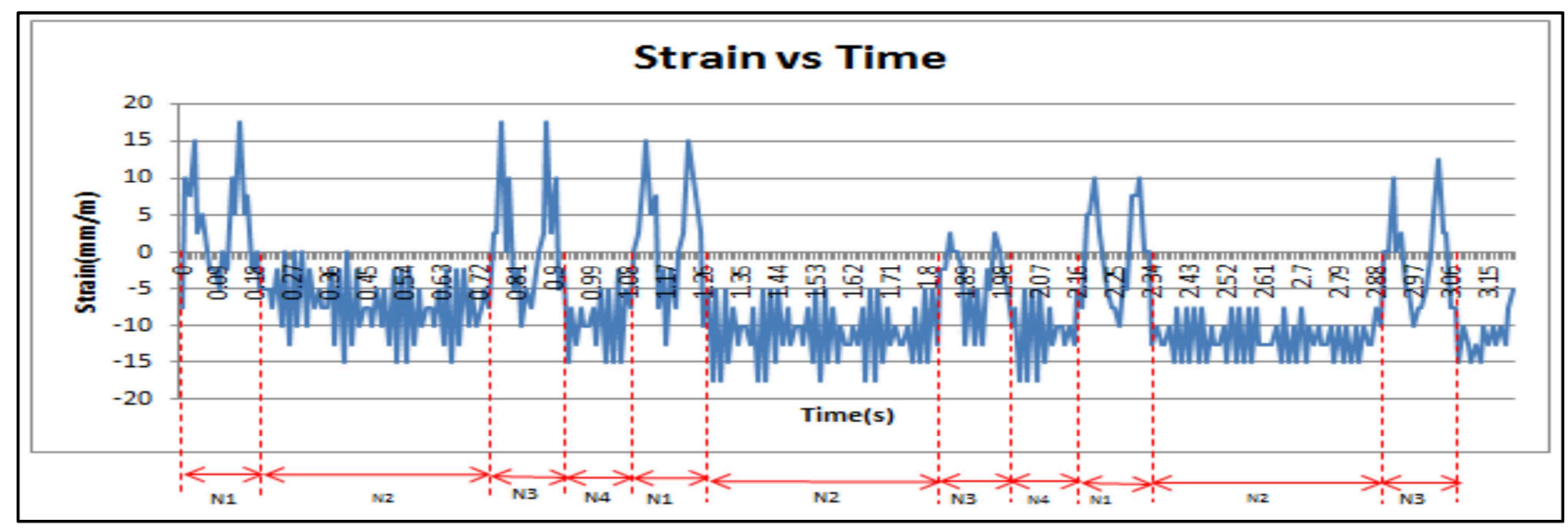

Figure 1: Analyse raw data

The raw data is divided into four n-sections for every coach that is N1, N2, and N3 as shown in Figure 2. N1 is front wheel. There are two wheels for the front wheel. Next, N2 is distance between front wheel, N1 and back wheel, N3. N3 is back wheel and consist of two wheels. Finally, N4 is distance from back wheel, N3 of the coaches to front of the wheel, N1 for the next coaches. The diagram below shows the position of $\mathrm{N}$-section.

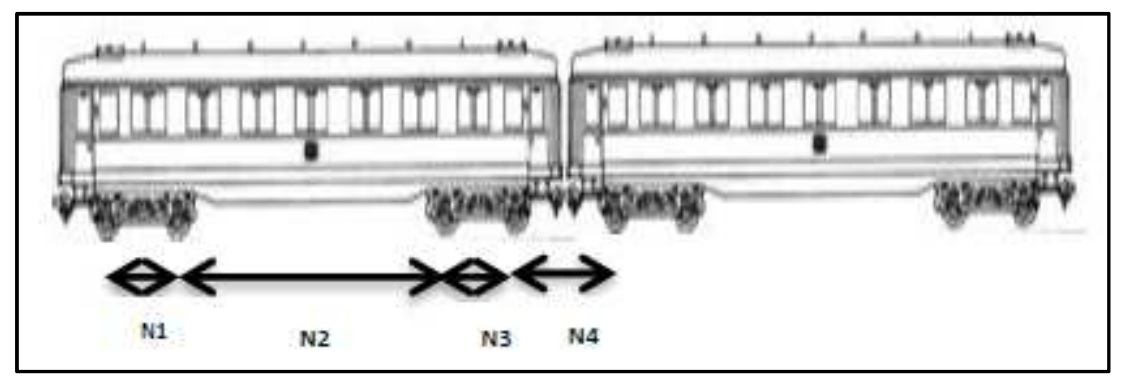

Figure 2: N-section of train

Determination Constant Amplitude. Every data was divided into N-section. To determine the constant amplitude, calculation of using strain ratio method was used for every divided $\mathrm{N}$-section. Firstly, the value of $\varepsilon_{\min }$ and $\varepsilon_{\max }$ was obtained from the data by selecting the minimum value of strain and maximum value of strain respectively for every section of $\mathrm{N}$. Eq. 1 was calculated to determine the origin value for the graph. After that, the value of strain ratio, $\mathrm{R}$ was calculated using Eq.2. Next, the values of strain of amplitude, Ea are calculating using Eq. 3. After all the data was 
obtained, the graph was plotted. One cycle for the graph consist of four data that starting with Emean $+\varepsilon a$, Emean, Emean - Ea, and finish with Emean. Table 1 shows data for section n1-1. After this value calculated, the graph can be plotted with the same value of amplitude. The value for one cycle is determined by adding and subtracting the value of Eamplitude and Emean.

$$
\begin{aligned}
& \text { Emean }=\frac{\text { Estrain data }}{\text { no. of data }} \\
& \mathrm{R}=\frac{\text { Emin }}{\text { Emax }} \\
& \varepsilon \mathrm{a}=\frac{1-R}{1+R}
\end{aligned}
$$

\begin{tabular}{|c|c|c|c|c|c|c|c|c|c|c|c|c|c|c|c|c|c|c|c|c|}
\hline Tire(s) & 0 & & 002 & 0.13 & 00 & 005 & 0.6 & 007 & 0.08 & 009 & 01 & 0.11 & 012 & 113 & 0.14 & 0.15 & 016 & 0.17 & 0.18 & 019 \\
\hline in $(\operatorname{mm}(\mathbf{m})$ & .75 & 10 & 7.5 & 15 & $\mu$ & 5 & 0 & & re & .5 & & 2 & in & & $1 / 2$ & & 7.5 & $2 \pi$ & 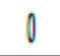 & . \\
\hline
\end{tabular}

Table 1: Time (s) vs Strain $(\mathrm{mm} / \mathrm{m})$

Rainflow Cyclic Counting. The calculation is conduct to determine the exact number of cycle of load applied on the PCS by the train passing through it. From the varying spectrum of raw data, a number of cycles can be obtained. The calculation of the rain flow counting method is depending on the peak and valley of the graph. The example of calculating using the rain flow counting method is illustrated as in Figure 3. P and v indicate peak and valley respectively. The region above graph call peak while the region under the graph called valley.

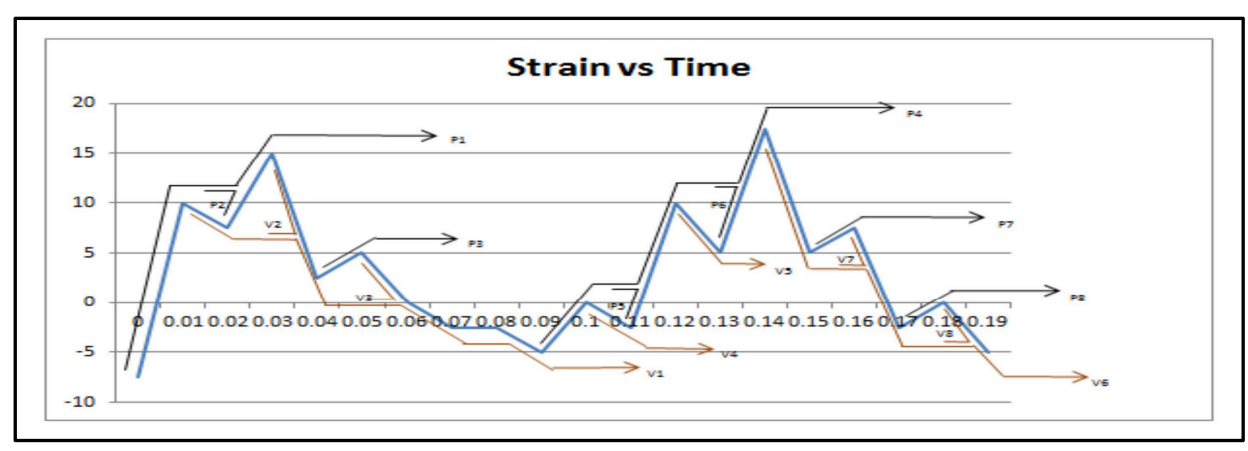

Figure 3: Rainflow counting method.

\section{Result}

The result was interpreted by combining both constant amplitude and the number of cycle. The Table 2 shows the result constant amplitude data for N1-1.Figure 4 were plotted using data from Table 2 that been constructed for every part in each data. The data was plotted for the raw data and the modified data with the number of cycle obtained by rain flow counting method and the constant value. Figure 4 shows the N-section for three coaches train that have been divided and converted into a constant graph data. Figure 1 shows the graph of variable data and Figure 4 is the graph of constant variable data. The train shows the location of the load when the section hit the PCS. The graph was plotted using Microsoft Excel software. 
Table 2: Complete constant amplitude data N1-1

\begin{tabular}{|c|c|c|c|c|c|}
\hline & Variable & olitude & Constant & plitude & No. of cycle \\
\hline Coaches & Time & Strain, $\varepsilon$ & Time & Strain, $\varepsilon$ & Cycle \\
\hline N1-1 & 0.00 & \begin{tabular}{|r|}
-7.50 \\
\end{tabular} & 0.00 & 10.06 & 8 \\
\hline N1-1 & 0.01 & 10.00 & 0.01 & 2.88 & 8 \\
\hline N1-1 & 0.02 & 7.50 & 0.01 & -4.31 & 8 \\
\hline N1-1 & 0.03 & 15.00 & 0.02 & 2.88 & 8 \\
\hline $\mathrm{N} 1-1$ & 0.04 & 250 & 0.03 & 10.06 & 8 \\
\hline N1-1 & 0.05 & 5.00 & 0.03 & 2.88 & 8 \\
\hline N1-1 & 0.06 & 0.00 & 0.04 & -4.31 & 8 \\
\hline N1-1 & 0.07 & -2.50 & 0.04 & 2.88 & 8 \\
\hline N1-1 & 0.08 & 2.50 & 0.05 & 10.06 & 8 \\
\hline N1-1 & 0.09 & -5.00 & 0.06 & 2.88 & 8 \\
\hline$N 1-1$ & 0.10 & 0,00 & 0.06 & -4.31 & 8 \\
\hline N1-1 & 0.11 & -2.50 & 0.07 & 2.88 & 8 \\
\hline N1-1 & 0.12 & 10.00 & 0.08 & 10,06 & 8 \\
\hline $\mathrm{N} 1-1$ & 0.13 & 5.00 & 0.08 & 2.88 & 8 \\
\hline $\mathrm{N} 1-1$ & 0.14 & 17.50 & 0.09 & -4.31 & 8 \\
\hline N1-1 & 0.15 & 5.00 & 0.09 & 2.88 & 8 \\
\hline N1-1 & 0.16 & 7.50 & 0.10 & 10.06 & 8 \\
\hline N1-1 & 0.17 & -2.50 & 0.11 & 2.88 & 8 \\
\hline $\mathrm{N} 1-1$ & 0.18 & 0,00 & 0.11 & -4.31 & 8 \\
\hline$N 1-1$ & 0.19 & -5.00 & 0.12 & 2.88 & 8 \\
\hline N1-1 & & & 0.13 & 10.06 & 8 \\
\hline N1-1 & & & 0.13 & 2.88 & 8 \\
\hline N1-1 & & & 0.14 & -4.31 & 8 \\
\hline $\mathrm{N} 1-1$ & & & 0.14 & 2,88 & 8 \\
\hline $\mathrm{N} 1-1$ & & & 0.15 & 10.06 & 8 \\
\hline N1-1 & & & 0.16 & 2.88 & 8 \\
\hline N1-1 & & & 0.16 & -4.31 & 8 \\
\hline N1-1 & & & 0.17 & 2.88 & 8 \\
\hline$N 1-1$ & & & 0.18 & 10.06 & 8 \\
\hline N1-1 & & & 0.18 & 2.88 & 8 \\
\hline N1-1 & & & 0.19 & -4.31 & 8 \\
\hline $\mathrm{N} 1-1$ & & & 0.19 & 2.88 & 8 \\
\hline
\end{tabular}

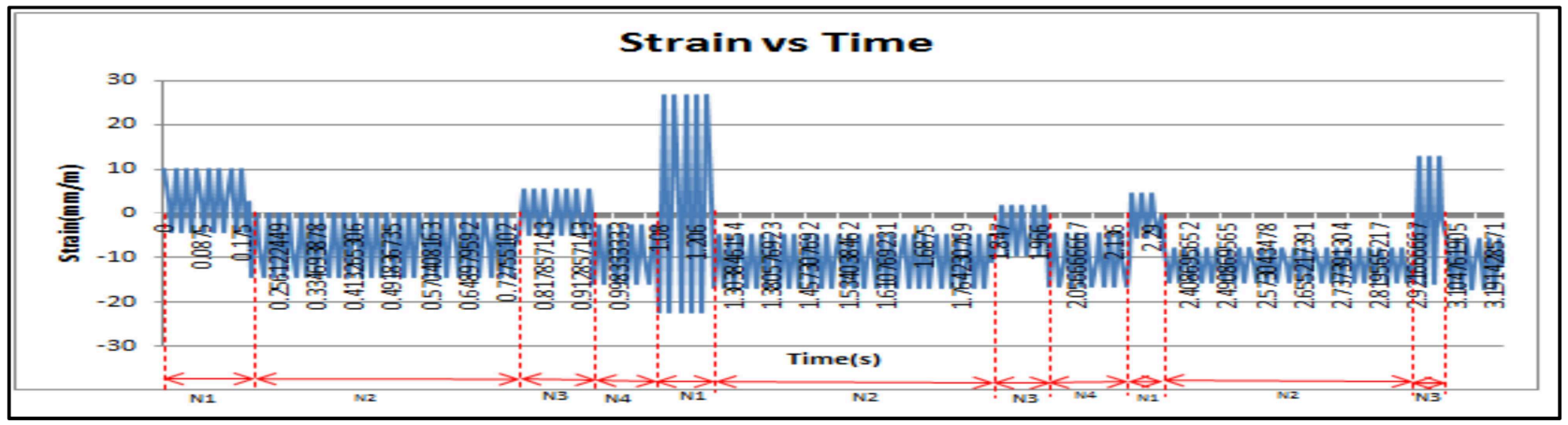

Figure 4: Constant amplitude graph

\section{Discussion}

From the graph, its shows the pattern of load applied to the PCS. The higher value occurs usually at $\mathrm{n} 1$ and $\mathrm{n} 3$ where the wheels of train pass through the PCS. This is because the load from the train is transferred to the ground using the wheel of train. From the tire the load is transferred to the PCS. In addition, the distance between the tires shows a small value of strain. This is because the PCS is vibrating due to the incoming load from the incoming wheels. Other than that, the vibration along the rail attached to PCS is the other reason why the PCS produced the small value of strain in n4. 
The constant amplitude data was divided into n-sections to classify the load when the wheel of train pass through the PCS and the load applied when the PCS is vibrating due to incoming load. The load impact to PCS from the constant value amplitude is the same as the variable value amplitude even though the pattern of graph is different. From the tabulate data in Table 2, there is a different point of the strain and time for variable amplitude and constant amplitude because of the number of cycle calculated using rain flow counting method. The actual number of cycle is applied to the constant amplitude value.

\section{Conclusion}

From the result, the value of constant amplitude was determined using a formula that stated earlier. The value of raw data was converting into the constant value. The data pattern can be determined as the higher value of strain occurred when wheels of the train hit the PCS[6]. In addition, the number of cycle also was calculated using rain flow counting method. By applying this method, the actual number of cycle can be obtained from the variable amplitude data. Based on this research, the higher strain value for three coaches train is $55.4762 \mathrm{~mm} / \mathrm{m}$ due to several data.

\section{Acknowledgement}

The authors would like to express their sincere gratitude to Ministry of Higher Education Malaysia (MOHE) for the funding under FRGS scheme (600-RMI/FRGS 5/3 (100/2013)) and Keretapi Tanah Melayu Berhad (KTMB) for providing the much needed onsite data capturing. Special thanks to Research Management Institute (RMI) and Faculty of Civil Engineering, UiTM Shah Alam for providing facilities and guidance that helped this research to be completed.

\section{References}

[1] N. I. Sharul, E. Dozier, A. Afidah, H. Siti Hawa, and R. Mohd Ikmal Fazlan, Loading Capacity of Prestressed Concrete Sleeper Under Harmonic Function, Applied Mechanics and Materials (2014) 118-122.

[2] KTMB, Keterapi Tanah Melayu Berhad, 2012.

[3] T. Thierfelder and E. Sandstrom, The creosote content of used railway crossties as compared with European stipulations for hazardous waste, Sci. Total Environ. 402 (2008) 106-12.

[4] S. Kaewunruen and A. Remennikov, Dynamic Crack Propagations in Prestressed Concrete Sleepers in Railway Track Systems Subjected to Severe Impact Loads, Journal of Structural Engineering 136 (2010) 749-754.

[5] D. Edmund, A. Abu-Bakar, S. H. Hamzah, and R. M. I. F., Flexural and Cylces Determination of Prestressed Concrete Sleeper (PCS) Subjected to Train Wheels Movement by Using Rainflow Method, Curtin University of Technology Science and Engineering International Conference 6 November 2012.

[6] M. R. Salim, A. Abu-Bakar, and A. A. Shariff, Investigation on simulation of train loading on prestressed concrete sleepers, Applied Mechanics and Materials 157 (2012) 666-670. 